Journal of Social Sciences 1 (1): 31-38, 2005

ISSN 1549-3652

(C) Science Publications, 2005

\title{
Firms and their Responsibility towards Nature
}

\author{
Jérôme Ballet and Damien Bazin \\ The Center for Economics and Ethics in the Environment and Development \\ University of Versailles - $S^{t}$ Quentin-en-Yvelines (UVSQ), France
}

\begin{abstract}
Corporate social responsibility is increasingly discussed in economics and management studies today. Corporate leaders often make use of this concept, which finds its origins in philosophy, to analyse the normative behaviour of their companies. But what exactly is corporate responsibility? Is it a mere concept currently in vogue, or is it a new structural approach which could indeed take responsibility into account insofar as long-term environmental preservation is concerned? In order to answer this question, this study first proposes a reading of "stakeholders". This approach poses several problems when dealing with corporate responsibility regarding the preservation of nature. Secondly, it presents a more detailed analysis of such corporate social responsibility and the problems it poses. The debate regarding action with the interest of its outcome and action in the interest of the action itself is the focal point of present discussion.
\end{abstract}

Key words: Firms, Ecology, Nature, Responsibility, Stakeholders

\section{INTRODUCTION}

Taxation is a frequently used tool in environmental preservation. State intervention thus seems the best way to protect nature. Such a concept is based on the hypothesis that economic agents are not responsible. However, overlooking such an absence of responsibility could lead to bad environmental quality, especially since State intervention could produce a crowding-out effect upon responsibility. It would lead the economic agents to believe that: "since I pay for the environment, nothing can stop me making use of it, even in an abusive manner". Taxation could hence lead, in certain cases, to environmental degradation. It is thus of prime importance to take responsible behaviour into account in the definition of taxation. First upon the list is corporate responsibility. Corporate responsibility has today become a classical dilemma amongst managers. It has undergone various developments, be it mainly through the numerous journals which have dedicated several articles to this question (such as the Business Ethics Quarterly, Journal of Business Ethics, Ethical Enterprise etc). One of the main problem points in the past few years seems to be the complex relationship between responsibility and nature. The present study is aimed at reviewing this delicate relationship. The responsibility of a firm was essentially developed upon a social base, from which the term 'corporate social responsibility' originated. Enlargement towards a societal base does not appear to be problematic as long as we do not take the aspect of nature into account. However, taking this aspect into account does indeed reveal itself to be extremely problematic. It does not seem to favour the mode of reasoning which analysts have preferred until now. The reasoning in vogue led to and refers to the theory of stakeholders. This mode of reasoning solely takes human beings into consideration. This could hence be categorized as an anthropocentric approach. Furthermore, the importance of these stakeholders greatly depends on the reciprocal interests which the firm and the stakeholders themselves could achieve through their relationship. Does the natural environment then have any meaning as a stakeholder? In other words, could and would a firm consider nature as an interested party, thus rendering nature a partner in its evolution? Various approaches have attempted to deal with this enlargement. It is indeed a delicate matter to define the interests of nature. This would imply a restriction of the firm's responsibility if it does not take the preservation of nature seriously into account. The spokespersons for nature could of course have an interest in defending nature. But this approach to the problem does not offer a total solution. We would thus have to deal with the problematic of responsibility from a renewed angle of approach. This angle is mainly based on the interest in the act of preserving nature as it is. This new perspective, based on a bio-ontocentric design, puts forward an original conception regarding a firm's responsibility where taking the natural environment into account is not merely desired but also necessary, through an ethical attitude.

Taking a Closer Look at Environmental Responsibility: Present discussion is often centred upon responsibility towards nature. The least responsible behaviour would then be represented by not being concerned about oneself or the other. The fact that the environment is polluted or not is of little importance to the economic agent. In our opinion, this situation is exceptional since there rarely could exist such insensitivity. Nevertheless, imposing a tax for ecological reasons lies on the idea that economic agents do not act in a responsible manner. Then, the internalisation of externalities should be imposed in an authoritarian manner by the planner, through taxation (incentives) and through intergenerational transfers. 
Environmental economists such as Howarth and Norgaard [1] justify State intervention through the weak presence of responsibility within economic agents. They have attempted to prove that responsibility could be understood through altruism. The uniqueness of this model lies in the fact that it demonstrates that the externality which originates from production does not affect domestic utility but rather, the level of production. One of the characteristics of this model is that it highlights that altruism withers with time. We are thus faced with a shortcoming of altruistic behaviour (which in turn requires the intervention of public authorities). On reading the works of Howarth and Norgaard, it seems that the internalisation of environmental or intergenerational externalities does not in itself guarantee intergenerational equity. The distribution of inheritance between generations determines if allocations of resources prevents the decrease of well-being between generations. The ethical argument is that future generations have the right to hope for a heritage which would enable them to have for themselves a certain level of well-being similar in goods and/or natural capital to that of the previous generation. The quest of equity could be undertaken by a social planner through the offering of compensation to future generations for the environmental damage caused. However, this would then imply that there exists a certain mechanism which makes such transfers possible.

This does not however imply that responsibility is never taken into account. Laffont [2] and Collard [3], for example, introduce the concept of morality as a constraint upon the allocation and the distribution of resources. But the focal point of their analysis consists only in solving the problem of coordination as it appears in the prisoner's dilemma. What we could conclude from the categorical imperative adapted to economic theory is that it is subject to conditionality. An individual will undertake an action only if everybody else does the same. Others economists like Roemer [4] propose an integration of responsibility following the principles of Rawls and by mixing handicap (positive and negative) to merit (positive and negative). However, Roemer does not succeed in well explaining individual responsibility: responsibility is the task of the Ministry (Equality of Opportunities). If the State is defined as guarantor of responsibility, this would then imply to a certain extent that the individuals are not responsible. It is the imposition, to a certain degree, of an artificial responsibility which functions solely through coercion or encouragement.

Since the inclusion of the concept of responsibility, recent works have oriented economic analysis towards a durable and systemic approach. Economists have however been unable to satisfactorily develop the concept of Responsibility from a global point of view.

The fact that the question of responsibility has not been given enough thought implies that environmental preoccupations are traditionally dealt with by the State. The State intervenes, through a system of taxation, in order to counter pollution. Within this framework, taxation fis perceived as an obligation to be responsible. Nevertheless, we cannot cast aside responsible behaviour. Certain firms adopt a particular type of responsible behaviour. Phillips and Reichart [5], for example, illustrate their analysis concerning environmental responsibility of firms with the use of cases such as the Body Shop or Tom's of Maine. Similarly, Gendron [6] highlights that we are now noticing in Quebec the emergence of a new concept of ecological ethics specific to political leaders and distinct from "new social movements" (i.e. citizens or managers).

However, taking responsibility into account also implies a questioning the idea that environmental preservation is uniquely and traditionally ensured through taxation. More precisely, we consider that the imposition of a tax brings about an absence of responsibility. This logic implies that State intervention produces a crowding-out effect on responsible behaviour. Frey [7] for example, applies the crowdingout theory to environmental morality. This crowdingout effect upon private voluntary contributions has been highlighted on numerous occasions [8-10]. Taking responsibility into account implies clearly distinguishing it from behaviour pertaining to taxation. On the one hand, taxation directly improves the quality of the environment [11] but on the other, through the reduction of responsible behaviour, taxation induces an indirect effect on environmental degradation. More recently, we notice an emergence of various propositions integrating this crowding-out effect. Their conclusions partly contrast with those of Howarth and Norgaard [1]. In the Howarth-Norgaard model, the insufficiency of intergenerational altruism implies the necessary intervention of the state whereas these new models conclude that State intervention via taxation reduces responsible behaviour. Several conclusions could be drawn from this model. Firstly, an increase in taxes could lead to the degradation of the environment. This indeed is not the aim of taxation. Next, when the State planner takes responsible behaviour into account, it would enable us to obtain a better quality of the environment in a situation where the effects of responsibility are not taken into account.

Taking responsibility towards nature into consideration opposes, to a certain extent, the premise of state intervention. It obliges us to deal with behaviour regarding taxation from an ethical perspective.

Integrating Responsibility Towards Nature: What Perspectives For Firms?: Reflections on the corporate social responsibility are not new. They resemble an ethics of responsibility, in opposition to the ethics of conviction as specified by Max Weber. Alfred Marshall, for example, in a text dated $17^{\text {th }}$ November 1875 and entitled Some Features of American Industry has described the influence of the form of industrial development in America and Western Europe upon the ethics which predominate in these regions. In his 
History of economic analysis Schumpeter complains that Austrian universities were mainly teaching this subject instead of "sound economic theory". Similarly in the $19^{\text {th }}$ century, F. Le Play was to become one of the founders of corporate ethics. Since of late, corporate social responsibility has been associated to the theory of Stakeholders. Though the origin of the stakeholder theory dates back to the 1960s or even the 1930s [12], it is however, Freeman [13] who brought it to the front light. The theory of stakeholders attempts to find out the origins of the requests addressed to the company and also tries to determine which requests the company should primarily take into account. A request for responsibility refers to the demands and claims of individuals or groups of individuals who show a certain interest in the company. We would thus have to construct a broader reflection relative to the interactions between the company and society, bearing in mind both shareholders and stakeholders (NGOs, consumers).

As such, if we consider that a firm is responsible and that it should create processes of response as well as other programmes and policies which conform to its actions, we would then have to question the extent of the firm's responsibility. Otherwise stated, to which requests should one fulfil and what policies should the firm establish when it takes all these requests into account?

This leads to a certain classification of requests and therefore a classification of responses. The theory of stakeholders deals precisely with this question. The propositions which refer to this theory are twofold. Firstly, propositions aimed at determining 'who counts' and what is the maximum extension of the circle of stakeholders. Secondly, propositions aimed at elaborating a classification of stakeholders, based on diverse criteria in order to facilitate the management of a firm's responses. Since this second set of propositions do not enter into the debates referred to in this study, we shall only deal with the first set of propositions.

Two visions exist in regard to the first aspect i.e. who should be taken into account? They could be defined as narrow and broad visions. The broad stakeholder vision is also proposed Freeman [13], also considered as the founder of this concept. According to him 'A stakeholder in an organisation is (by definition) any group or individual who can affect or is affected by the achievement of the organisation's objectives'.

On the other hand, Clarkson has presented us with one of the narrowest definitions [14]. According to him, stakeholders are groups or individuals who voluntarily or involuntarily face a risk because of the company. Those who voluntarily run a risk are those who invest in the company, whatever be the form of investment (material, human, financial etc). Meanwhile, those who involuntarily run a risk are individuals who are placed in a situation of vulnerability because of the company's activity.

The stakeholder controversy between these two visions deals with the extent of a firm's responsibilities. It deals with the question that should be taken into account when enforcing a strategic policy conforming to principles of responsibility. However, the question takes on a whole new meaning when we introduce nonhuman elements into the field of company responsibility and when these elements, especially the natural environment, are introduced into the debate.

The paradigm shift faced by Society in general and societies in particular, necessitates a rethinking of our analytical framework and taking the environmental problematic into account, this time not merely as an 'ecologist' ideology (having, at its best, a "marketing effect"), but rather, as a real, objective stake. Indeed, the Fordist paradigm has led to a new paradigm based on the notion of sustainable development as the basis of progress. Thus, the consideration of sustainable development strategies directly assists in opening a company to its socio-economic and natural environment. Company strategies aimed at sustainable development actually require systemic modes of solution i.e. taking into account the holistic impact on ecosystems and societies [15-17]. These strategies thus refer to several relations which are external to the company. These relations include diverse groups of actors and of course, clients and suppliers, but they also include actors such as environmental awareness associations. The need for social relations to establish such solutions thus appears to be evident. As such, the necessary information for the creation of a strategy based on sustainable development shall require a relational investment in various communities because of the market's inability to furnish such information [18].

However, the establishment of a relationship between strategies of sustainable development, represented by the taking into account of the natural environment and the opening up of the company to society takes us back to the question of enlargement of the theory of stakeholders. Several attempts in integrating the natural environment into this theory have been proposed. They are either centred on an anthropocentric perspective, according to which humans enjoy priority over nonhuman life forms, or on a bio-centric perspective which defends the idea according to which all members of all species are considered on an equal footing.

This integration leads to the initial framework of the theory of stakeholders. In an optic of strategic management, this initial framework is defined by two important characteristics. Firstly, this theory is based on the notion of interest. Put more precisely, it is based on the idea that the company opens unto its environment because reciprocal interests are expected from one and the other. The company enters into contact with the stakeholders because this, in its eyes, represents a method for obtaining information and could thereby serve in refining its predictions on the demands and expectations of its environment. Next, the stakeholders taken into account are solely human beings. Stakeholders could be extremely diverse i.e., suppliers, clients, associations for the protection of the environment, consumer protection associations, human 
rights leagues etc, but they constitute, in all cases, a direct relationship to the demands forwarded by humans.

The attempts presented here are incorporated into the enlargement of the theory of stakeholders in order to offer non-humans, most importantly the natural environment, a similar status to that of humans. We shall now discuss an attempt based on biocentrism and another based on anthropocentrism to show the limits of each of these approaches.

Starik [17] attempted to broaden the theory to nonhuman participants within a bio centric perspective. In order to do this, he uses the concept of "Gaïa" and that of the 'living planetary system'- a naturalist and Aristotelian hypothesis, first forwarded by Lovelock [19]. Planet earth is perceived as a gigantic living organism capable of autoregulation and auto adjustment in regard to exogenous shocks, without human action. On a more philosophical note, this idea replies to the notion of 'biotic communities' through the concept of Land Ethic. For the author, these foundations seem to represent a diachronic link between humans and other living beings: 'Human beings, plants, animals, earth and water are all linked to a community which presents great activity composed of cooperation and competition, a biotope', [20].

According to Orts and Strudler [21], however, Starik's [17] work is aimed more at convincing managers, rather than proposing a real academic discussion. As such, the broad theory of stakeholders, within a biocentric perspective, has not been able to avoid critiques.

In order to be valid and to comply with the theory of stakeholders, this perspective should, as a matter of fact, assume that the natural environment could have interests of its own. We shall now proceed to discuss this problematic.

Could the natural environment have interests of its own? This implies that these interests could be identified even though they cannot be expressed. Moreover, the notion of interests refers, within this theoretical framework, to needs and desires which in turn become demands. It is however difficult to speak of nature's desires and still less of its demands. The utilitarian vision of interest is not valid for nature since nature is unable to express what is good or bad for itself.

In a biocentric approach, on the other hand, nature can undergo suffering. A first attempt in integrating nature into the stakeholder theory could thus be initiated upon this basis. The consideration of various ecological domains serves as a reference, for example, in distinguishing flourishing domains and those which are undergoing irreversible degradations. This distinction would help introduce the concept of the needs of nature. Let us take, for example, a field where a farmer has sprayed pesticides and chemical fertilizers to such an extent that it no longer yields anything, not a single crop nor flora could grow anymore. In such a case, it is clearly evident that the earth needs to be disintoxicated or decontaminated before it could once again produce a crop. Admittance of the notion of need does not, however, imply that the earth would have any interest in this decontamination. This reveals that one could identify a need but not an interest. Similarly, a damaged work of art needs to be restored, but this not imply that it has an interest in being restored; a car, meanwhile, needs petrol to function, but we cannot state that it has an interest in having petrol. The very notion of need could itself be questioned. The needs as expressed here are anthropocentric. The painting needs to be restored only if man wishes to conserve it. Similarly, the field needs to be decontaminated only to be used by man. It hardly seems possible to define an interest of nature through these observations. Nor is it possible to identify a need of nature. This undoubtedly casts shadows over attempts to broaden the theory of stakeholders.

Let us nevertheless admit that one could go beyond this first critic. Let us then suppose that objects could indeed have personal interests. In other words, that nature, as an object, could have it own interests. We would then face a second critic, this time forwarded by Sagoff [22]. His critic could be presented as follows: Let us imagine that an object could have needs and that it would cease to exist if these needs are not met. In this case, it is possible to consider that the object has a certain interest in the satisfaction of its needs. Admittance of this relation between a need and interest of an object does not, however, identify the object. Indeed, if the natural environment could be considered as an object, this reasoning could then be applied to it, but other objects could also enter into the equation. As such, saying that the natural environment could have interests implies that all objects could have interests- a natural resort, just as a work of art, a building or even a table. Such an assumption leads us to a shortcoming in the theory of stakeholders. How could a company decide to whom it should give priority? To a chair or to a table? We would thus require a special technique which would enable the weighting of objects' interests in order to classify them in order of priority. Such reasoning does not seem very convincing in giving nature priority. But there indeed is no doubt that the natural environment could not stand on the same level as a chair or a building.

Indeed, although we could clearly admit that certain plants and animals have needs, this does not, however, imply the need for preserving an animal species or a certain variety of plants. This is because the very meaning of evolution itself implies the creation and destruction of species. As such, we cannot derive, through the concept of needs, a clearly identifiable group of interests other than those of humans.

Orts and Studler [21] thus consider that Starik's attempts cannot be upheld. They nevertheless stress that it is not incoherent to state that nature as such has no interest of its own and it therefore has no interest to be preserved, but, at the same time and as a moral question, the respect of nature requires its preservation. The example of the maltreatment of animals clearly illustrates this point. Legislation now prohibits the 
maltreatment of animals, not because of their right to life or because man hunts or slaughters them for food or mere pleasure, but rather, civilised society prohibits such action because it seems degrading for man to brutalise them.

A second possibility in integrating natural environment into the theory of stakeholders is through human interest for nature. We could thus construct an anthropocentric approach. Phillips and Reichart [5] are the main references regarding this approach. According to them, the theory of stakeholders could take the natural environment into account through human interests, in other words, through human stakeholders who are concerned by nature. Even though nature in itself could not be considered as a stakeholder, the theory of stakeholders could produce a moral reason to protect the natural environment since human stakeholders are concerned about it. As such, the interests of spokespersons, environmental activists and NGOs could be to defend nature or, more precisely, to defend the preservation of certain elements.

These authors see examples of such reasoning in certain environment-friendly companies such as The Body Shop. It actually is quite the opposite. Competition pushes companies to look for openings in the market where they could invest and which would enable them to distinguish themselves from their competitors. Within this context of reasoning, the protection of the environment is thus a mere marketing tool, just like any others. Companies would invest in it only as long as it brings them gains. There is hence no reason to believe that there could be any responsible behaviour vis-à-vis the environment. Even though cases of double dividends (profit and the protection of the environment), or even triple dividends (profit, protection of the environment and creation of jobs) exist, these double and triple dividends cannot, however, be generalised. Moreover, situations where the search for profit has caused great environmental damage are indeed quite frequent. We could nevertheless notice a certain category of behaviour on the part of consumers and shareholders who are in favour of increasing the various forms of a particular company's responsibilities. This does not, however, solve the question pertaining to nature's priority over other forms of societal investment.

Moreover, the objective of Phillips and Reichart [5] is not to create a general principle which could be adopted by all reasonable beings, but rather, highlights that the theory of stakeholders, as a method for taking nature into account, cannot easily be cast away.

However, there still remains one obstacle. The conflicting interests between any stakeholders still persist. This, as shown by Evans and Freeman [23], is nevertheless an important problem. As the number of stakeholders increases, so too does the risk of conflicting interests. This implies that the natural environment is treated as any other social problem or as any other interests demanded by any stakeholder. Finally, this would imply that man does not take the question of the protection of nature seriously. We would therefore require an alternative mode of reasoning. This however does not mean that we should refute the theory of stakeholders, but rather, that we may have to interpret it in a different way. As stated by Freeman, the theory of stakeholders should be interpreted as a 'genre of stories about how we live' [24]. This new mode of reasoning would probably require us to give an inherent value to nature "since only this value could help us be aware of environmental preoccupations which cannot be explained through the notions of instrumental and intrinsic values" [25]. This value thus adds a moral consideration which could be translated by the obligations of an individual towards this particular value.

A New Approach: The theory of stakeholders, taken as a final product of developments pertaining to company responsibility, no doubt represents a very interesting analytical perspective. Its fault, however, lies in its incapacity to seriously consider the natural environment as a specific domain which should merit a company's attention. The arguments that follow reach beyond this perspective. The discussion shall comprise of three stages. Firstly, the theory of stakeholders as an analysis of company responsibility is one amongst many methods in dealing with the problem. It would be judicious to directly refer to ethics rather than make reference to a management perspective. Secondly, a moral perspective is compatible to the concept of interest. This concept only takes on a specific meaning. Finally, once these two arguments which would enable us to elaborate the ethical responsibilities of a company have been established, we shall analyse the integration of the natural environment as an extension of this responsibility. The specificity of the environmental stake shall then enable us to arrive at a priority in taking the preservation of nature into account. This approach is based on a bio-ontocentric approach. This concept highlights the reciprocal relations between organisms and their environment. It is based on the consciousness and acknowledgement of the natural limits imposed upon economic growth. The conceptual base of bio-ontocentrism is biocentrism whose ethical extension is aimed at ontology, i.e. whose principle is the protection of life, where life has a value of its own. The first stage of our attempts in rethinking company responsibility is aimed at analysing the extent to which the theory of stakeholders, as a method grasping this responsibility, represents just one particular and instrumental vision of ethics. The theory of stakeholders, especially the narrower version of this theory, is mainly based on the consideration of a company's and individuals' reciprocal interests. In other words, the latter is interested in seeing the company make profit, while the company, in turn, has a certain "interest" in taking the individuals' requests into account, if it is to remain efficient. This method is wholly comprehensible if looked at through a managerial optic. The company attempts to discover the 
demands and claims of its socio-economic environment. The anticipation of these exigencies enables the company to provide better answers, with greater speed and efficiency. The company thus saves a certain amount of negotiation and adjustment costs and creates for itself an image of responsibility before society. However, this mode of reasoning makes responsibility an instrumental ethical notion.

Consideration of the other uniquely based upon the demands he puts forward, or which he could potentially put forward, especially regarding the reduction of costs, renders the other a means to an end. This end represents the quest of personal interest. This of course, does not imply that the consideration of the demands of the socio-economic environment is necessarily instrumental. Rather, it merely implies that it becomes instrumental if the consideration of this environment is done solely in order to achieve one of the company's objectives. Still, the relationship between stakeholders and reciprocal interest seems to confirm this instrumental vision.

Although a certain number of moral propositions, including utilitarianism, seem to comply with this vision, other moral traditions firmly oppose such a vision. Kantian moral philosophy is such an example. What we wish to highlight at this point is the singular character of the responsible process based on the theory of stakeholders. As such, the rejection of the broadening of this theory through the integration of nature does not remove all possibilities of creating a certain responsibility for the company regarding nature. The broadening of Kantian moral philosophy is one possibility. Moreover, Kantian moral philosophy is compatible with certain aspects of the theory of stakeholders, such as the notions of interest and vulnerability and thus risk. The second phase thus consists in dealing with the notion of interest.

The theory of stakeholders refers to the notion of interest. However, this concept could be dealt with in a relatively different perspective than that of the managerial optic. We would have to distinguish between acting in the name of an interest other than duty and acting in the name of interest itself. Thus, as notes by Rawls [26], an action accomplished out of duty is not an action without interest, but rather, an action carried out for duty itself "An action done for the sake of duty is one from an interest taken in the action itself as correctly answering, or so we think, the principles of practical reason". The fact that an action is accomplished out of interest for the action itself renders this a moral action. As such, as Rawls, states, all action is triggered by interest. One must understand that there is no action triggered solely by reason and that a reasonable action is also triggered by interest, an interest for the action itself. Only moral actions depend on an interest for the action itself. Non moral actions, meanwhile, depend on the interest for the objective which would be achieved upon completion of the act. An action would of course have to conform to the categorical imperative if it is to be considered moral.
Morality thus presupposes the respect of two stages. Firstly, the interest which triggers the action should be an interest for the action itself. Next, the action should comply with the maxim of action "Act only according to the maxim. As such, you could want while it becomes a universal law" [27].

This distinction between acting out of interest and conceptualising an interest adds a motivational structure to action [28, 29]. This structure gives priority to practical interest regarding moral principles over interests concerning objects of need and desire. As stated yet again by Rawls [26] "this means that the interest moving our actions are of different kinds and arranged in a certain structure with the practical interest we take in the moral law itself, so far as we have a good will, always having an effective regulative priority". This does not however imply that interests for the object of action are incompatible with the interest for moral law. An individual who acts magnanimously and with compassion towards others but gains satisfaction through his action does not however carry out an action which is contrary to moral law. Nevertheless, we cannot assume that it is his feelings that give a moral character to his action. As such, even though an individual shows no feeling, or is totally insensitive, moral action still remains the same. Moreover, the interest for the action gives priority to the respect of moral principles. Even in this case, the individual accomplishes what is required from him by duty because of the motivational structure which gives priority to interest for action over interest for the end result achieved through action.

The notion of interest is thus not incompatible with morality. Rather, it takes on a particular meaning because the lexical structure of motivations encourages action i.e. because of the classification of motivations which offers a systematic priority to moral motivation over all other motivation.

It now remains to be shown that nature can be preserved because of an interest for the action of preservation in itself, or, in other words, that the preservation of nature corresponds to principles of ethics. Jonas [30], going against the modern wave of thought and thereby joining antiquity's naturalism, reintegrates nature into his moral dimension. He thus offers us a grid of analysis which could be employed in our reasoning.

The respect of nature first deals in finding out whether it possesses a moral signification or not. We would first have to recompose man/nature relationships through the principle of responsibility if we are to answer this question. Jonas enlarges the Kantian moral perspective by reforming the categorical imperative as follows: "Act so that the effects of your action are compatible with the permanence of genuine human life' or 'Act so that the effects of your action are not destructive to the future possibility of such a life" [30]. Through this imperative, Jonas attempts to comply with the new dimensions of responsibility.

This responsibility, always according to Jonas, obliges us to transmit, to the following generations, an 
environment which would enable life to continue. Taking life into account thus implies the necessity to take account of historical time through the notion of irreversibility (such as the degradation of bio-diversity). Thus, for Jonas, the duty of humanity is, before all, bio-ontological. Ontology considers life as a whole and thus requires the respect of each place and each object. Jonas does not, in order to achieve this, attempt to positively found the preservation of humanity, but rather, he poses the existential base upon free action and which is thus conditional of man. Jonas thus moves away from "bio spherical egalitarianism". This concept goes against his own philosophy. It advocates a responsible and therefore ethical, human being. However, according the same value to all living beings excludes all responsibility. Jonas increasingly refers to a categorical differentiation between beings and thus, through extension, between the environments wherein these beings evolve (such as nature reserves or, still closer to us, parks and gardens or water which should not be polluted). This implies that certain species should be protected because they have a certain "intrinsic vulnerability" within them.

Ontology, here, does not refer to an arbitrary action which advocates the accomplishment of an aesthetic preference (such as nature, for example), but rather, it proposes a rational ethical base. As such, Jonas' response to the nihilistic challenge could be observed through the application of a "preliminary metaphysical field' which highlights the possibility that the presence of a world is preferable to the absence of one", Dewitte [31] develops this idea by showing that Jonas accords a human "yes" which is considered as the extension of the affirmation of a being's value which has already occurred in the being itself. This implies and demonstrates that a finality evolves and distinguishes itself differently from conscience and human desire. Let us however not forget that an ethical attitude is possible solely with and for man. Does this mean that nature cannot be ethical? Indeed, nature is not and shall never be, ethical. It is precisely because it cannot be ethical that man is required to be ethical with nature. As such, man becomes the subject of responsibility and nature, the object. Nature thereby claims its rights without having any duties. Nature is recognised as such but has no obligation towards man even though man himself has obligations towards nature. This is because man is born of nature. Thus, having obligations implies that nature enforces obligations upon itself. According to Kant, however, the capacity of self constraint is above all, a human characteristic. This leads us to believe that nature has rights, including the right to life. The fact that it possesses only rights and nothing else makes it vulnerable since it is incapable of making others respect its own rights. Man thus has the duty of responsibility towards nature.

Nature, according to Jonas is thus perceived as fragile and vulnerable. Although Jonas' arguments are categorical, Jonas does not, however, advocate an absolute "wilderness". While rejecting a purely anthropological approach, Jonas believes that nature needs man in order to exist and thus, man should integrate himself into his natural environment. Jonas hence proposes the creation of mechanisms of prevention and protection through the bio-ontological concept. The originality of this author is to totally break away from traditional anthropocentric ethics. At first sight, we may consider that putting man in the forefront (cf. future generations), could represent an anthropocentric method. Asserting this does not suffice. The finality of responsibility does not lie within man and for man, but rather, in the permanence of being.

According nature an ethical meaning admits a moral interest for the action of preserving nature. Here, we do not deal with an interest for an objective achieved by the action which would be the well-being of future generations. Rather, we deal with an interest for the action in itself, where it relates to a moral motivation. This reasoning complies with the Kantian method previously elaborated in two stages: the interest for the action itself which relates to the moral motivation and the categorical imperative as formulated by Jonas. It is hereafter not incompatible to think that nature represents an interest for a company and, more specifically, that nature gives it priority because of the lexical classification of moral motivations.

Within such a perspective, the use of the term "interest party" instead of stakeholders is a semantic variation with a particular meaning. This semantic variation enables us to differentiate between possessing a stake and representing a concerned party. Although their role as stakeholders could be contested, NGOs, company organisations as well as scientific circles, for example, still represent concerned parties taking part in the debate on climate changes.

\section{CONCLUSION}

Environmental responsibility is not uniquely reserved to the domain of taxation. Said otherwise, taxation could provoke a crowding- out effect over responsibility. It would then be useful to introduce corporate social responsibility into this analysis.

Corporate social responsibility has undergone several developments which have led to the theory of stakeholders. Attempts to broaden this theory, whether they be founded upon an anthropocentric or bio-centric perspective, seem to face several major difficulties. Biocentrism, for example, faces a major difficulty. Indeed, adopting such a point of view implies that nature, as a finality in itself, has the capacity to impose ethical norms upon man. Taken as a system of domination, this vision is just as limited as anthropocentrism (opposite reasoning).

These two approaches remain entirely normative (absence of rules of conduct) and only indicates a system of values, most often anthropocentric, to which an individual adheres. This inability to achieve a certain normative standard (judgement of values which 
includes duty), leads these approaches to systematically answer to the dysfunctionings of the natural environment. Consideration of the natural environment could only be grasped at an ultimate level, that of philosophical ethics which requires a great degree of abstraction; the bio-ontological approach is one such illustration. This approach has several advantages. Firstly, it considers the natural environment seriously and gives it a systematic priority over other objects of responsibility. The preservation of life offers priority, in an ethical perspective, to the action of preservation itself, beyond the consequences of what this may imply. Next, this approach is compatible with the theory of stakeholders on several important points such as the notion of interest and vulnerability, even though these very notions take on a new dimension. Finally, this approach remains coherent with the perspective of human responsibility (man being the guarantor of nature)

\section{REFERENCES}

1. Howarth, R.B. and R.B. Norgaard, 1992. Environmental valuation under sustainable development. The American Econ. Rev., 2: 473-477.

2. Laffont, J.J., 1977. Effets externes et théorie économique. Paris : éditions du CNRS, collection. Monographie du séminaire d'économétrie.

3. Collard, D.A., 1978. Altruism and Economy: A Study in Non Selfish Economics. New York: Oxford University.

4. Roemer, J.E., 1996. Theories of Distributive Justice. Cambridge (Mass.): Harvard University Press.

5. Phillips, R.A. and J. Reichart, 2000. The environment as a stakeholder? A fairness-based approach. J. Business Ethics, 23: 185-197.

6. Gendron, C., 2003. De la reconnaissance à l'engagement : représentations et éthique de l'environnement et du développement durable chez les hauts dirigeants du Québec. Entreprise Ethique, $16: 41-48$.

7. Frey, B.S., 1992. Pricing and regulating affect environmental ethics. Environmental and Resource Economics, 2: 399-414.

8. Reece, W.S., 1979. Charitable contributions: new evidence on household behavior. American Econ. Rev., 69: 142-151.

9. Kingma, B.R., 1989. An accurate measurement of the crowd-out effect, income effect and price effect for charitable contributions. J. Political Econ., 97: 1197-1207.

10. Khanna, L. and T. Sandler, 2000. Partners in giving: the crowding-in effects of UK government grants. European Econ. Rev., 44: 1543-1556.

11. Frey, B.S., 1999. Morality and rationality in environmental policy. J. Consumer Policy, 22: 395417.

12. Preston, L.E. and H.J. Sapienza, 1990. Stakeholder management and corporate performance. J. Behavioural Econ., 19: 361-375.
13. Freeman, R.E., 1984. Strategic Management: A Stakeholder Approach. Boston: Pitman-Ballinger.

14. Clarkson, M.B.E., 1995. A stakeholder framework for analysing and evaluating corporate social performance. Academy of Management Review, 20: 92-117.

15. Gladwin, T.N., J.J. Kennelly and T.S. Krause, 1995. Shifting paradigms for sustainable development: implications for management theory and research. Academy of Management Review, 20: 874-907.

16. Shrivastava, P., 1995. The role of corporations in achieving ecological sustainability. Academy of Management Review, 20: 936-960.

17. Starik, M. and G.P. Rands, 1995. Weaving and integrated web: multilevel and multisystem perspective of ecologically sustainable organizations. Academy Management Review, 20: 908-935.

18. Bouty, I., 2000 Interpersonal and interaction influences on informal resource exchange between r\&d researches across organizational boundaries. Academy of Management J., 43: 50-65.

19. Lovelock, J., 1988. The Ages of Gaïa: A Biography of Our Living Earth. New York: W.W Norton.

20. Leopold, A., 1953. Round River. New York: Oxford University Press.

21. Orts, E.W. and A. Strudler, 2002. The ethical and environmental limits of stakeholder theory. Business Ethics Quarterly, 12: 215-233.

22. Sagoff, M., 1974. On preserving the natural environment. Yale Law J., 84: 205-267.

23. Evans, W.M. and R.E. Freeman, 1993. Ethical Theory and Business. New Jersey: Englewood Cliffs.

24. Freeman, R.E., 1994. The politics of stakeholder theory: some future directions. Business Ethics Quarterly, 4: 409-422.

25. Desjardins, J.R., 1995. Environmental Ethics: An Introduction to Environmental Philosophy. Belmont: Wadsworth Thomson Learning.

26. Rawls, J., 2000. Lectures on the History of Moral Philosophy. Harvard: Harvard University Press.

27. Kant, I., 1785. Foundations of the Metaphysics of Morals. Translated with an introduction by L. White Beck. New York: Macmillan.

28. Herman, B., 1981. On the value of acting from the motive of duty. Philosophical Rev., 40: 359-382.

29. Allison, H., 1990. Kant's Theory of Freedom. Cambridge: Cambridge University Press.

30. Jonas, H., 1984. The Imperative of Responsibility. In Search of An Ethics for the Technological Age. Translated by H. Jonas with the collaboration of D. Herr. Chicago: The University of Chicago Press.

31. Dewitte, J., 1993. La réfutation du nihilisme, réflexions sur les fondements métaphysiques de l'éthique de la responsabilité. Paris : Vrin. 